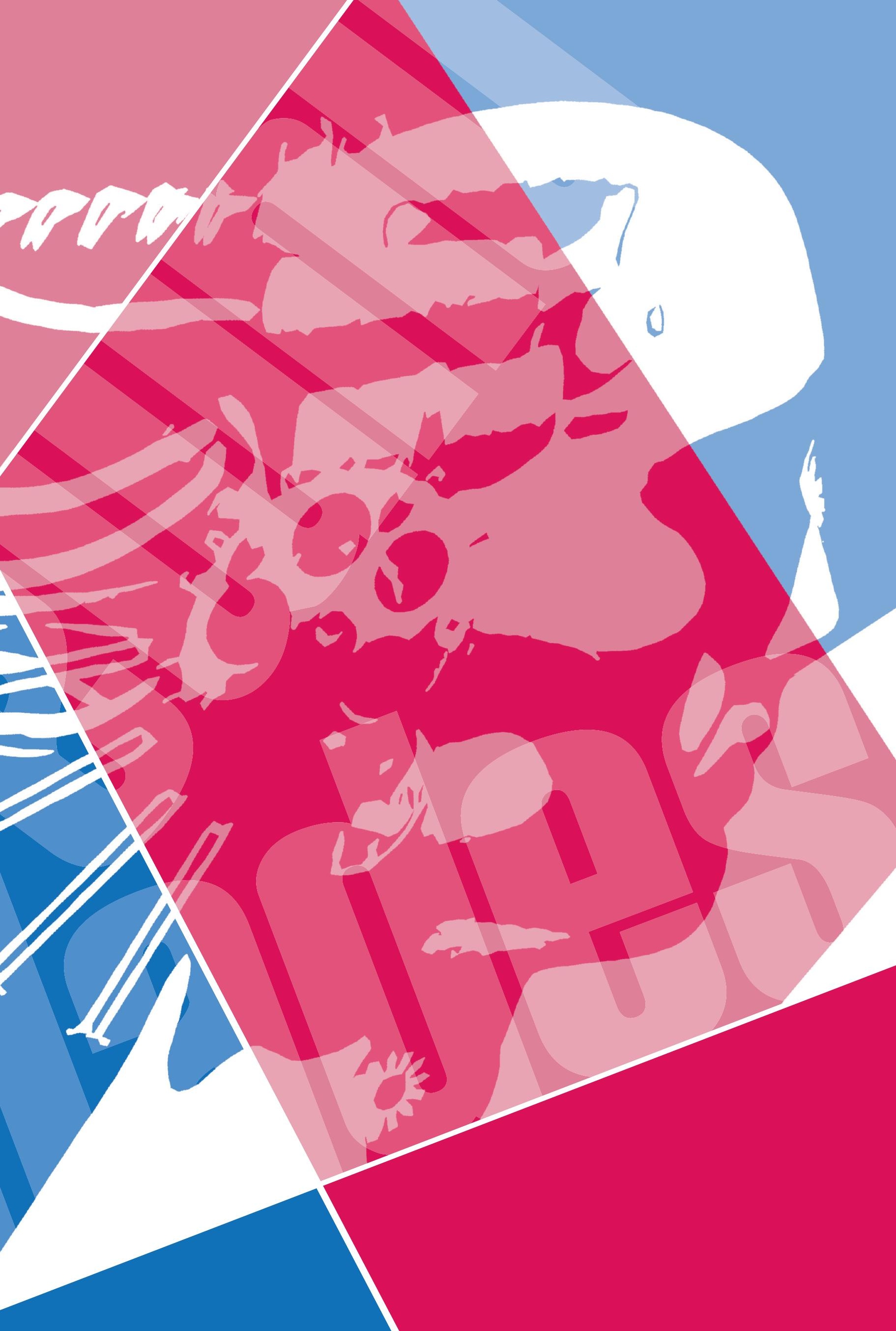




\section{LUCIA SANTAELLA}

LUCIA SANTAELLA

é professora da PUC-SP e autora de, entre outros,

Navegar no Ciberespaço

- O Perfil Cognitivo do

Leitor Imersivo (Paulus).

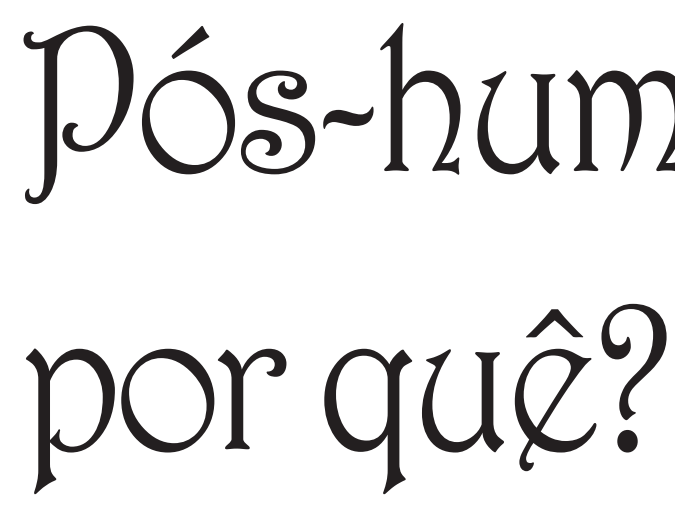




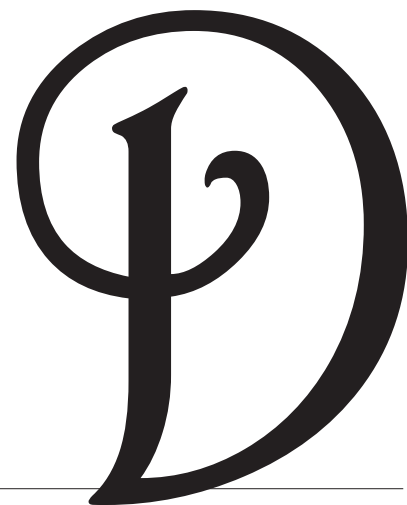

esde meados do século XX, com o desenvolvimento acelerado das tecnologias digitais, especialmente a partir da convergência explosiva do computador e das telecomunicações, as sociedades complexas foram crescentemente desenvolvendo uma habilidade surpreendente para armazenar e recuperar informações, tornando-as instantaneamente disponíveis em diferentes formas para quaisquer lugares. Pela mediação de interfaces do ser humano com as máquinas, o mundo está se tornando uma gigantesca rede de troca de informações. Se podemos estar certos de alguma coisa a respeito do futuro é que a influência da tecnologia digital continuará a crescer e a modificar grandemente os modos como nos expressamos, nos comunicamos, ensinamos e aprendemos, os modos como percebemos, pensamos e interagimos no mundo.

O quadro que se apresenta é impressionante. Kaku (2001, p. 18) sublinha que o conhecimento humano duplica a cada dez anos. Nas últimas décadas, foi gerado mais conhecimento científico do que em toda a história humana. O número de seqüências de DNA que podemos analisar duplica a cada dois anos. Quase diariamente, as manchetes proclamam novos avanços em computação, telecomunicações, biotecnologia e exploração do espaço. Mas essas mudanças rápidas, atordoantes, não são apenas quantitativas. "Elas assinalam as dores do parto de uma nova era."

De fato, hoje são poucos aqueles que ainda duvidam disso, tanto é que já parece existir um certo consenso de que a revolução tecnológica que estamos atravessando é psíquica, cultural e socialmente muito mais profunda do que foi a invenção do alfabeto, do que foi também a revolução provocada pela invenção de Gutenberg. Para muitos analistas do social as mutações são vastas e profundas, atingindo proporções antropológicas tão ou mais impactantes do que foram as da revolução neolítica.

Os prognósticos atuais, no campo emergente da computação "pervasiva” ou onipresente, indicam com alguma segurança que nossos estilos de vida serão fatalmente alterados quando os microchips se tornarem tão abundantes que sistemas inteligentes serão espalhados aos milhões em todo canto de nosso ambiente, incorporados às paredes, aos móveis, aos nossos aparelhos, nossa casa, nosso carro, penetrando na estrutura de nossas vidas. Os ambientes irão se tornar inteligentes, transformando tudo à nossa volta, inclusive a natureza do comércio, a riqueza das nações e o modo como nos comunicamos, trabalhamos, nos divertimos e vivemos. Em vez de se tornarem os monstros vorazes retratados nos filmes de ficção científica, os computadores ficarão tão pequenos e onipresentes que se tornarão invisíveis, estando em toda parte e em lugar nenhum, tão poderosos que desaparecerão de nossas vista. Esses dispositivos invisíveis vão se comunicar uns com os outros e se conectar automaticamente à Internet, que se desenvolverá até transformar-se em uma membrana composta por milhões de redes computacionais de um planeta inteligente (Kaku, 2001, p. 29).

\section{PRESSENTIMENTOS CONSUMADOS}

É curioso observar que, em meados dos anos 1980, quando a Internet estava emergindo e a simbiose entre os seres humanos e as máquinas apenas se insinuava, em um tipo de ficção que passou a ser conhecida sob a rubrica de ciberpunk, jovens escritores já pressentiam os desenvolvimentos e complexidades do estado atual e futuramente prometido das tecnologias. Em 1986, Sterling (apud Dyens, 2001, p. 73) dizia:

“A tecnologia dos anos 1980 cola-se à pele, responde ao toque: o computador pessoal, o walkman, o telefone portátil, as lentes de contato. Alguns temas centrais emergem repetidamente no ciberpunk. O tema da invasão dos corpos: membros prostéticos, circuito implantado, cirurgia plástica, alteração genética. O tema ainda mais poderoso da invasão da mente: interfaces 
cérebro-computador, inteligência artificial, neuroquímica - técnicas que radicalmente redefinem a natureza da humanidade, a natureza do eu... Sendo híbridos eles mesmos, os ciberpunks são fascinados pelas interzonas".

A palavra ciberpunk começou a ser usada, em 1983, por Gardner Dozois, editor da Isaac Asimov's Science Fiction Magazine, a partir de uma história homônima escrita por Bruce Bethke (verLemos, 2004). Desde então, o termo passou a designar um tipo de ficção científica com características comuns que encontram sua exemplaridade na obra Neuromancer (1984), de William Gibson. Nessa história, a personagem, como sanção por um dano cometido, é banida da imersão em ambientes virtuais e condenada a viver aprisionada nos limites de seu próprio corpo. A construção de seres etéreos, de puro software por meio da inteligência artificial, sugerida nessa novela, atingiu um clímax de popularidade depois do sucesso recente alcançado pela série de filmes Matrix e seus games correspondentes.

Nesse gênero de literatura, que une a ficção científica com outros códigos genéricos populares, o estilo e as figuras do movimento punk se amalgamam com outras subculturas urbanas contestadoras. Segundo Kellner (2001, p. 383), o punk denota “a rispidez e a atitude dura da vida urbana em aspectos como o sexo, as drogas, a violência e a rebeldia contra o autoritarismo no modo de viver, na cultura pop e na moda". Os dois termos juntos, ciber e punk, "referem-se ao casamento da subcultura high-tech com as culturas marginalizadas das ruas, ou à tecnoconsciência e à cultura que fundem tecnologia de ponta com a alteração dos sentidos, da mente e da vida presente nas subculturas boêmias".

O movimento ciberpunk abraça as tecnologias, mas de maneira rebelde, à margem da lei, contra o Estado centralizador e as grandes estruturas econômico-financeiras, sendo favorável, portanto, “a um uso subcultural mais descentralizado da ciência e da tecnologia a serviço dos indivíduos". Desse modo, enxerga "a tecnologia como algo onipresente, mas que apresenta novas possibilidades para o prazer e a liberdade do indivíduo, bem como para sua destruição e escravização" (Kellner, 2001, pp. 383 , 402). Ao fim e ao cabo, para Kellner (2001, p. 402), a ficção ciberpunk acaba propondo

“[...] profundas questões filosóficas sobre a natureza da realidade, da subjetividade e do ser humano no mundo da tecnologia: o que é autenticamente humano quando se tornam indefinidas as fronteiras entre humanidade e tecnologia? O que é identidade humana, se ela for programável? O que sobra das noções de autenticidade e identidade numa implosão programada entre tecnologia e ser humano? O que é 'realidade', se ela é capaz de tanta simulação? De que modo a realidade está hoje sendo corroída, e quais são as conseqüências disso? Certamente, Gibson não responde a essas perguntas, mas pelo menos suas obras as formulam e nos obrigam a pensar sobre elas".

Foi justamente no terreno sedimentado por esse tipo de ficção e pelas inquietações e indagações nela presentes que a expressão "pós-humano" gradativamente tomou corpo. Conforme já indiquei em outra ocasião (Santaella, 2003, p. 191), expressões similares, tais como "autômata bioinformático", "biomaquinal”, "pós-biológico”, foram aparecendo cada vez mais assiduamente em publicações de arte e cultura cibernéticas até que, em meados dos anos 1990, todas elas consolidaram-se no caldo da cibercultura emergente. O sema comum que as une encontra-se no hibridismo do humano com algo maquínico-informático, que estende o humano para além de si. Assim, a condição pós-humana diz respeito à natureza da virtualidade, genética, vida inorgânica, ciborgues, inteligência distribuída, incorporando biologia, engenharia e sistemas de informação. Por isso mesmo, os significados mais evidentes, que são costumeiramente associados à expressão "pós-humano", unem-se às inquietações acerca do destino biônico do corpo humano 


\section{CORPOS PÓS-HUMANOS}

Segundo Dyens (2001, pp. 2-3), nossos corpos são agora feitos de máquinas, imagens e informações. Os corpos vivos estão borrados, moldados e transformados pela tecnologia e a cultura está tomando conta da biosfera. Do mesmo modo, Hayles (1996, p. 12) considera que o pós-humano representa a construção do corpo como parte de um circuito integrado de informação e matéria que inclui componentes humanos e não-humanos, tanto chips de silício quanto tecidos orgânicos, bits de informação e bits de carne e osso.

Um tal recorte semântico, pressagiando o futuro de uma outra espécie de corpo, nas interfaces do humano e do maquínico, é aquele que, sem dúvida, tem dominado no entendimento do pós-humano. Esse predomínio tem sido grandemente devido à apropriação política que as feministas fizeram da expressão. O interesse das feministas nas tecnologias políticas do corpo resulta do papel que o corpo, como figura socialmente construída, desempenha nos modos pelos quais a cultura é processada e orientada (Halberstam \& Livingston, 1995). Reivindicar a existência de corpos pós-humanos significa deslocar, tirar do lugar, as velhas identidades e orientações hierárquicas, patriarcais, centradas em valores masculinos.

Nesse contexto ficou mundialmente famoso o "Manifesto Ciborgue: Ciência, Tecnologia e Feminismo-socialista ao Final do Século XX”, de Donna Haraway (1985), no qual é proposta uma leitura progressista e feminista do mito do ciborgue. Com seu questionamento das dicotomias ocidentais entre mente/corpo, organismo/máquina, natureza/cultura, antinomias estas que também davam suporte ao patriarcado, a idéia do ciborgue penetrou intensamente na cultura, colocando em questão não apenas a relação do humano com a tecnologia, mas a própria ontologia do sujeito humano (ver Härtel \& Schade, 2000).

Embora tenhanotabilizadootermo"ciborgue", não foi Haraway quem o inventou. Nascido da junção de $c y b($ ernetic)+org(anism), cib(ernético)+org(anismo), foram Clynes e Nathan Kline, em 1960, que criaram a palavra, inspirados noexperimento com orato de Rockland, cuja bomba injetava em seu corpo doses controladas de substâncias químicas. Com o conceito de ciborgue, essa dupla buscava descrevero "homem ampliado", melhor adaptado para as viagens espaciais por meio de um coração controlado por injeções de anfetamina e pulmões substituídos por uma "célula energética inversa", alimentada por energia nuclear. Desde então, a idéia de um ser humano ampliado pelas tecnologias começou a se generalizar e, quando Haraway fez uso do termo, o imaginário cultural acerca desse ser híbrido já estava suficientemente fertilizado pelo cinema e pela TV (ver Santaella, 2003, pp. 187-9).

São vários os termos aparentados a "ciborgue" e nas vizinhanças da idéia do pós-humano que foram sendo introduzidos com a finalidade de caracterizar a mutação dos corpos como fruto das simbioses do ser humano com as próteses tecnológicas. Para essa caracterização, desde 1998, nos meus trabalhos, e conforme explicitei em "O Corpo Biocibernético Revisitado" (Santaella, 2004, pp. 53-64), tenho utilizado preferencialmente o adjetivo "biocibernético" pelas razões que volto a enunciar abaixo.

O sentido que dou a essa palavra "biocibernético" é similar ao de "ciborgue" Entretanto, prefiro o termo "biocibernético", de um lado, porque "bio" apresenta significados mais abrangentes do que "org", e, de outro lado, porque "biocibernético" expõe a hibridização do biológico e do cibernético de maneira mais explícita, além de que não está culturalmente tão sobrecarregado quanto "ciborgue" com as conotações triunfalistas ou sombrias do imaginário fílmico e televisivo.

Vêm sendo utilizados alguns outros adjetivos para o corpo tecnologizado que ocupam regiões semânticas próximas às de biocibernético e de ciborgue, tais como “corpo protético”, “pós-orgânico”, “pósbiológico” e, na sequiência, "pós-humano". Embora a palavra "prótese" seja bem funcional para caracterizar as extensões tecnológicas do corpo, a meu ver o signi- 


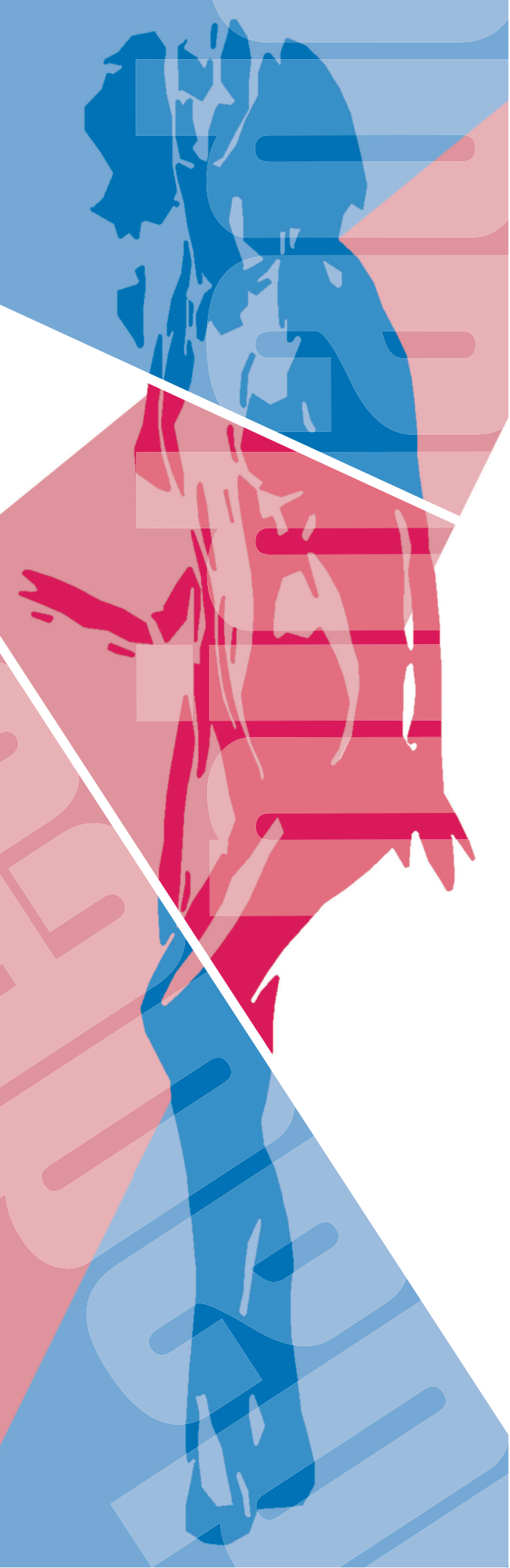

ficado dessa palavra ficou muito colado ao aspecto visível das extensões, idéia que busco evitar, visto que, cada vez mais, as extensões estão aderindo à fisicalidade de nossos corpos e habitando seus interiores, indicando uma tendência para se tornarem invisíveis e mesmo imperceptíveis.

As expressões "pós-orgânico"e "pós-biológico" também são repetidas com frequiência. Sob o título de OHomem Pós-orgânico. Corpo, Subjetividade e Tecnologias Digitais, Paula Sibilia (2002) considera que, embora a junção entre ser humano e tecnologia tenha sempre existido, ela está se aprofundando e se tornando mais crucial e problemática. Peças-chave na tecnociênciacontemporânea são a teleinformática e a biologia molecular. Nesse contexto, segundo a autora, surge uma possibilidade inusitada:

"O corpo humano, em sua antiga configuração biológica, estaria se tornando obsoleto. Intimidados pelas pressões de um meio ambiente amalgamado com o artifício, os corpos contemporâneos não conseguem fugir das tiranias (e das delícias) do upgrade. Um novo imperativo é internalizado, num jogo espiralado que mistura prazeres, saberes e poderes: o desejo de atingir a compatibilidade total com o tecnocosmos digitalizado. Para efetivar tal sonho é necessário recorrer à atualização tecnológica permanente: impõem-se, assim, os rituais do auto-upgrade cotidiano" (Sibilia, 2002, p. 13).

Para Sibilia, esses fenômenos enquadram-se na tradição fáustica do pensamento ocidental sobre a tecnociência, o qual enxerga nesta a possibilidade de transcender a condição humana. "Assim, valendo-se da nova alquimia tecnocientífica, o 'homem pós-biológico' teria condições de superar as limitações impostas pela sua organicidade, tanto em nível espacial quanto temporal" (Sibilia, 2002, p. 14).

Dando a "pós-biológico" um sentido distinto desse que é professado por Sibilia, Roy Ascott não o entende no plano ideológico de "certos sonhos fáusticos e gnósticos que aspiram à transcendência" e que "apelam para uma certa sacralização 
das tecnociências contemporânea, em sua fusão com o corpo humano, visando à libertação das restrições espaciais e temporais ligadas à materialidade orgânica”. Segundo Ascott(2003), o pós-biológico não se refere a sonhos, mas a processos reais, que nem sempre podem ser explicados como frutos de uma vontade humana demiúrgica, e que sinalizam a emergência de uma era úmida (moist) que está nascendo da junção do ser humano molhado (wet) com o silício seco (dry), e que se instalará especialmente a partir do desenvolvimento das nanotecnologias, as quais, bem abaixo da pele, passarão silenciosamente a interagir com as moléculas do corpo humano.

O significado com que emprego o adjetivo "biocibernético" é similar ao significado de "pós-biológico" para Ascott. Entretanto, quando me refiro às transformações corporais, continuo preferindo "biocibernético" porque, mais do que seus possíveis substitutos, esse adjetivo deixa explícita, como já foi mencionado acima, a hibridização indiscernível entre o orgânico-biológico e o maquínico-cibernético, entre a umidade do

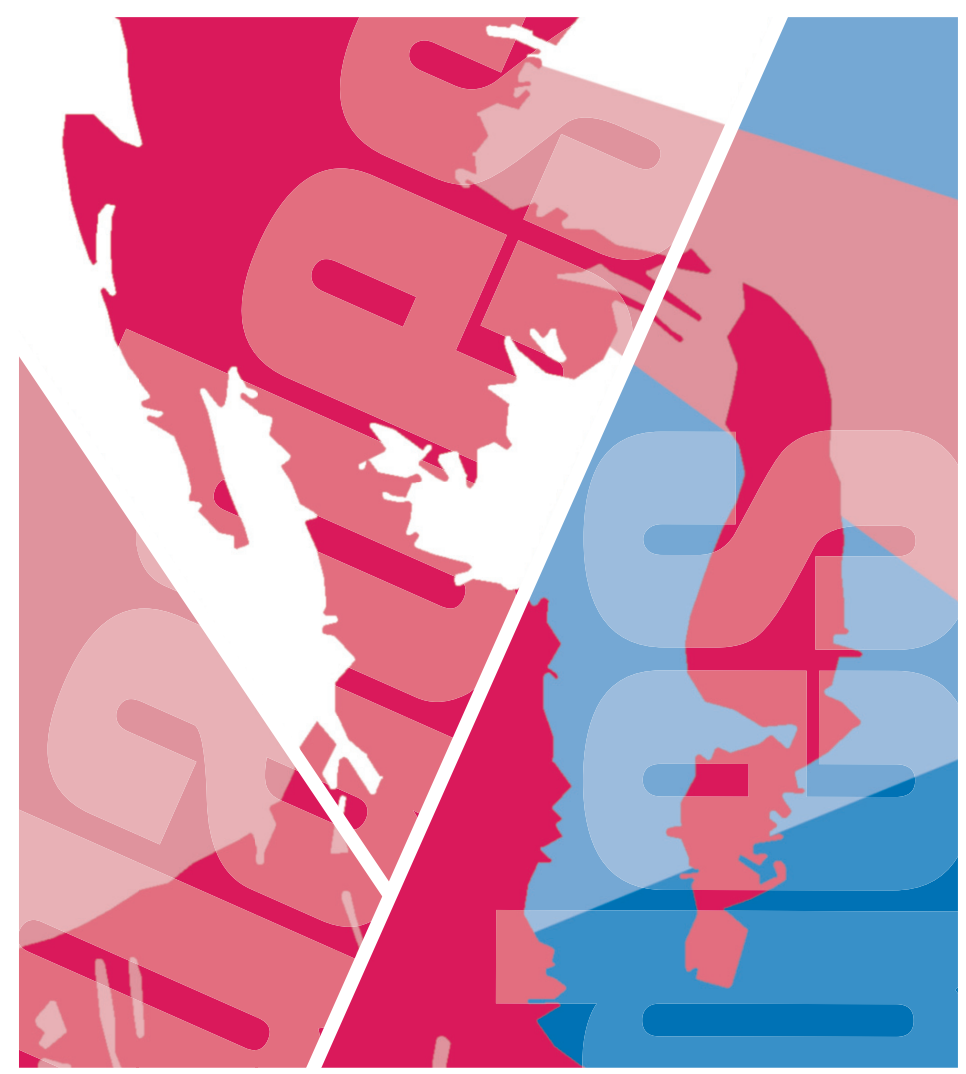

carbono e a secura do silício. Por mais que as tecnologias sedesenvolvame se sofistiquem, não as vejo como algo radicalmente estranho ao orgânico e biológico. São distintas, mas não estranhas. Tanto não são estranhas que estão hoje se misturando com o orgânico de maneira cada vez mais inextricável.

Quanto ao termo "pós-humano”, suas conotações certamente implicam, mas extrapolam de longe, a mera caracterização dos corpos. Não obstante incluam as mutações que as tecnologias estão provocando no real do corpo, há dimensões antropológicas e filosóficas implicadas nessa expressão que a dotam de uma complexidade que envolve, mas vai além da tecnologia e mesmo da biologia.

\section{A CONDICÃOO PÓS-HUMANA}

Embora o título do livro, Post-human Bodies (Halberstam \& Livingston, 1995), pareça restringir o "pós-humano" aos corpos, o conjunto de artigos de que o livro se compõe tem como alvo discutir as profundas mudanças tecnológicas, representacionais, sexuais e teóricas nas quais os corpos estão implicados. Para as organizadoras,

"Corpos pós-humanos são causas e efeitos de relações pós-modernas de poder e de prazer, virtualidade e realidade, sexo e suas conseqüências. $\mathrm{O}$ corpo pós-humano é uma tecnologia, uma tela, uma imagem projetada; é um corpo sob o signo da Aids, um corpo contaminado, um corpo morto, um corpo-tecno; ele é, como veremos, um corpo gay. O corpo humano em si não faz mais parte 'da família do homem', mas de um zôo de pós-humanidades" (Halberstam \& Livingston, 1995, p. 3).

As autoras argumentam que a história, concebida como história social e cronológica, está morrendo junto com o homem branco da metafísica ocidental. Por isso mesmo, os corpos pós-humanos não pertencem à história linear. São do passado e do futuro vividos como crise. Essa crise 
presente "não desliza suavemente ao longo de uma linha temporal unidimensional, mas irrompe e coalesce não localmente em um reino de significado que só é parcialmente temporalizável" (Halberstam \& Livingston, 1995, p. 4). Dentro desse ideário, os artigos do livro representam tentativas de dar conta do presente e processar identidades que "deixam traços nos corpos para se dissolverem no vórtice do que chamamos pós-modernismo, pós-humanismo, pós-colonialismo, capitalismo pós-industrial". Enfim, essa proliferação de "pós-ismos" marca, ainda segundo as autoras, simultaneamente, "a falha necessária e lastimável de se imaginar o que vem a seguir" e o reconhecimento daquilo que, no dizer de Derrida (1978, p. 293), sempre aparece como "o ainda não nomeável que se proclama e só pode fazê-lo, como é necessário, em qualquer momento em que um nascimento está para se dar, apenas sob a espécie da não-espécie, na ausência de forma, muda, infans, na forma aterradora da monstruosidade".

Na sua obra A Condição Pós-humana, o artista inglês Robert Pepperell (1995) afirma que a expressão “pós-humano" pode ser empregada em diversos sentidos. Os três sentidos em que ele a emprega podem delinear seu significado geral, a saber: em primeiro lugar, para marcar o fim do período de desenvolvimento social conhecido como humanismo, de modo que pós-humano vem a significar "depois do humanismo". Em segundo lugar, a expressão sinaliza o fato de que nossa visão do que constitui o humano está passando por profundas transformações. O que significa sermos humanos hoje nãoé mais pensado da mesma maneira em que era pensado anteriormente. Em terceiro lugar, "pós-humano" refere-se a uma convergência geral dos organismos com as tecnologias até o ponto de tornarem-se indistinguíveis. Para ele, essas tecnologias pós-humanas são: realidade virtual(RV), comunicação global, protética e nanotecnologia, redes neurais, algoritmos genéticos, manipulação genética e vida artificial. Tudo isso junto deve representar uma nova era no desenvolvimento humano, a era pós-humana.
Nessa mesma esteira de reflexão, Felinto (2006, p. 119) sublinha que o pós-humanismo pode ser entendido como "uma das mais relevantes 'narrativas digitais' com que nos defrontamos hoje - uma narrativa que encontra nos temas da transcendência, do espiritualismo tecnológico, da informatização do real e da expectação futurista utópica alguns de seus elementos principais". Todavia, ao tomar como base uma pesquisa cuidadosa realizada na Internet, Felinto toma a precaução de distinguir entre um pós-humanismo semeado na Internet versus um pós-humanismo crítico. De fato, quando se trata de uma questão como essa, sujeita a todos os tipos de exacerbação, há que se separar o joio do trigo. Senão vejamos.

\section{UM PÓS-HUMANISMO ILUSIONISTA}

A par de todas as instâncias de positividade que a Internet apresenta, ela também se constitui em terreno fértil para a proliferação de ideologias obscuras e superficiais. Quando se trata de um tema como o pós-humano, prenhe de instigações complicadas, nãoé de estranhar que a Internet abra o flanco para a expansão de interpretações impregnadas de misticismo, que compreendem o humano como um estágio transitório na evolução da inteligência. Na seqüência dessa evolução, o pós-humano significaria a superação das fragilidades e vulnerabilidades de nossa condição humana, sobretudo do nosso destino para o envelhecimento e a morte. Tal superação seria atingida pela substituição de nossa natureza biológica por uma outra natureza artificialmente produzida que não sofreria as limitações e constrangimentos de nosso ser orgânico, hoje obsoleto. A meu ver, além de simplista, reducionista, essa compreensão é ilusionista. Embora professe a idéia de uma evolução do ser humano biológico para um ser liberto dos limites do orgânico, falta a esse tipo de compreensão justamente uma visão mais clara do próprio evolucionismo e também 
do desenvolvimento antropológico da constituição simbólica do ser humano.

Certa está Sibilia (2002, p. 91) ao chamar de "impulsos neognósticos" uma tal "retórica mística e espiritualista, ligada aos novos dispositivos de sabere seus aparelhos tecnológicos". É nessa corrente que se encontram seitas radicais como a dos extropians (www. extropy.org), que professam uma filosofia "transumanista", na qual o humanismo é levado ao extremo, desafiando os limites humanos. Estes serão ultrapassados com a passagem para a condição transumana ou pós-humana.

Tais delírios pseudo-intelectuais, evidentemente, não podem ser tomados como definidores da problemática do pós-humano. Infelizmente, na sua obra competente e bem informada, Sibilia (2002) generaliza sua compreensão crítica do pós-humano dentro de um recorte que fixa a questão nas vizinhanças desses delírios. Ao citar um artigo publicado na Scientific American, no qual é afirmado que a evolução tecnológica é dez vezes mais veloz do que a evolução biológica, a autora lança uma pergunta, segundo ela, inevitável: "Como pretender que o velho corpo humano - tão primitivo em sua organicidade - não se torne obsoleto?". A resposta imediata é que estamos “inaugurando uma nova era: a da 'evolução pós-humana’ ou pós-evolução, que supera em velocidade e eficiência os lentos ritmos da evolução natural" (Sibilia, 2002, p. 15). A autora complementa:

“As novas potências dos homens contemporâneos parecem estar marcando uma ruptura, que muitos começam a apontar como o fim da humanidade (seja celebrando-o ou condenando-o) e o início de uma nova era: a pós-humanidade. Pois somente agora a criatura humana passaria a dispor, de fato, das condições técnicas necessárias para se autocriticar, tornando-se um gestor de si na administração do seu próprio capital privado e naescolha das opções disponíveis no mercado para modelar seu corpo e sua alma. Outro corte radical emerge da dissolução das velhas fronteiras entre o organismo natural-o corpo biológico-e os artifícios que a tecnociência coloca nas mãos do novo demiurgo humano para que ele conduza a pós-evolução, não apenas em nível individual como também quanto à espécie, hibridizando-se com as diversas próteses bioinformáticas que já estão à venda".

Embora, de fato, a condição pós-humana e a revolução biotecnológica que ela implica estejam colocando a humanidade diante de dilemas éticos inéditos, é preciso reconhecer que a separação pressuposta entre a evolução biológica e a evolução tecnológica pode ser improcedente. Se partirmos do pressuposto de que ambas as evoluções são inseparáveis, conforme foi brilhantemente discutido no livro de Merlin Donald, The Evolution of Modern Mind. Three Stages in the Evolution of Culture and Cognition (1991), a atual aceleração tecnocientífica não representa outra coisa senão o terceiro ciclo evolutivo do sapiens sapiens. Diante disso, longe de ser determinada apenas pelos sonhos de onipotência humana, a condição atual pode estar inscrita no programa genético da espécie humana, um programa que não é determinista, mas imprevisível, pois incorpora o acaso, e que teve início quando o humano se constituiu como tal, um ser paradoxal, natural e artificial ao mesmo tempo, pois a fala que faz do humano o que ele é desnaturaliza-o, coloca-o, de saída, fora da natureza. É muito justamente essa desnatureza congênita que a evolução tecnocientífica atual está nos fazendo enxergar em retrospectiva.

\section{POR UM PÓS-HUMANISMO CRÍTICO}

Tomando como base os argumentos de Donald e outros similares, conforme explanei em "Psicanálise e o Desafio do Pós-humano" (Santaella 2003,pp. 231-50), a meu ver, sem negar a originalidade das mutações que a tecnociência está atualmente introduzindo, não se pode deixar de considerar que elas estão na linha de continuidade 
e de aumento de complexidade daquilo que tenho chamado de crescimento dos signos na biosfera como fruto da externalização da capacidade simbólica humana (Santaella, 2003, pp. 209-30; 1996, pp. 183-94), algo que teve início no momento em que o ser humano se constituiu como tal através da posição bípede e da fala.

Trata-se de uma idéia similar àquela que é defendida por Serres (1986, apud Bruno, 1999, p. 102), quando chama o homem de animal cujo corpo abandona suas funções, lançando-as no exterior, onde adquirem novas funções. Assim, a boca evoluiu da captura do alimento para a fala, a mão deixou de ser pata e se soltou para pegar as coisas, e mesmo fabricá-las, e, então, para desenhar, escrever, etc.; a memória deixou o cérebro para passar ao papel e agora aos chips. Portanto, como lucidamente complementa Bruno (1999, p. 102),

“[...] o homem que 'abandona' o seu corpo é o homem que faz técnica, que se desprende do aqui e agora das circunstâncias, das imposições do meio ou das urgências vitais e produz, projeta o que não estava aí. É aquele, portanto, que estabelece com a natureza - com o seu corpo e com o seu meio - não uma simples relação de acomodação ou adaptação, mas de transformação. Desse modo, não é o corpo nu ou natural que estabelece a mediação ou a fronteira entre o homem e o mundo, mas um corpo atravessado, modulado pela técnica - não é por acaso que esta também se define como mediação. Mas isso não deve conduzir à suposição de que a técnica seja um mero prolongamento das funções do corpo - aí compreendidas as cognitivas -, pois, ao disseminar suas funções no espaço externo, nem o corpo, nem o mundo permanecem os mesmos - o interior e o exterior, bem como a mediação entre eles, ganham novos contornos".

Na mesma linha de pensamento, lançando mão de um arco-íris histórico muito extenso, as idéias que tenho publicado buscam reintegrar as posições fragmentárias que têm surgido no contexto do pós-humano.

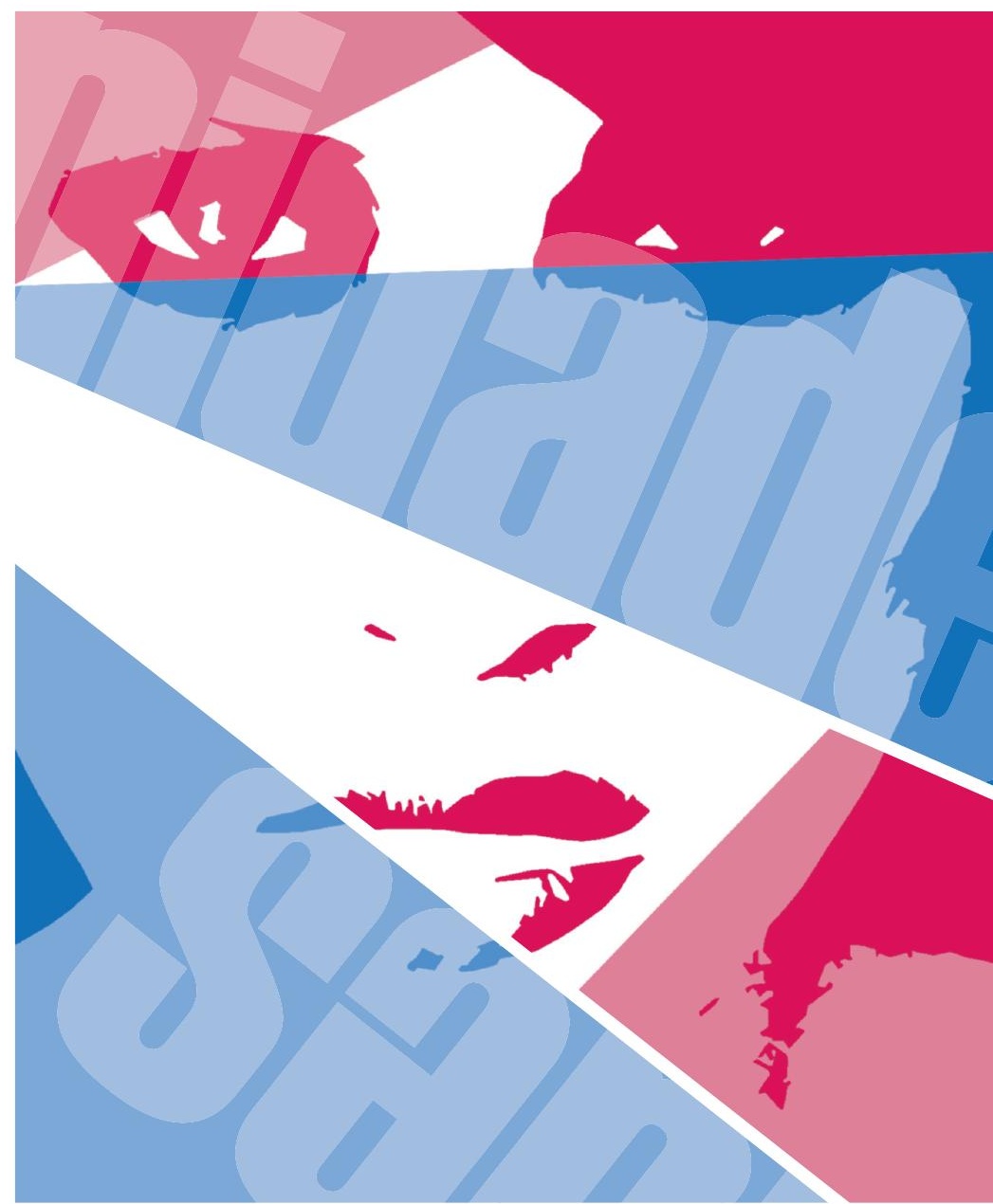

De fato, se continuarmos a alimentar a separação do corpo e da mente, da mente e do cérebro, se continuarmos a alimentar a dissociação entre esses últimos e as tecnologias, o inconsciente e destes entre si, as reflexões sobre o pós-humanismo só poderão ficar atravancadas em estreitos pontos de vista parciais. Para evitar isso, defendo a tese de que a técnica, hoje transmutada em tecnologia, remonta às origens da constituição do ser humano como ser simbólico, ser de linguagem, de modo que as tecnologias atuais estão em uma linha de continuidade e representam uma crescente complexificação de um princípio que já se instalou de saída na instauração do humano. Embora sob o disfarce insuspeito da naturalidade, a primeira tecnologia simbólica está no nosso próprio corpo: a tecnologia da fala. Certo estava Freud ao constatar, depois da virada dos anos 1920, que o ser falante é um animal desnaturalizado. A fala 
nos arranca do mundo natural e nos coloca, sem retorno possível, no artifício. Falar não é natural. Natural é sugar, chupar, comer, respirar. Falar, cantar, beijar, chorar e rir são funções inseparáveis de um mesmo artifício, o artifício da maquinaria simbólica que está instalada em nosso próprio corpo. Dessa primeira maquinaria, de cuja fabricaçãonão participamos, pois ela foi paradoxalmente instalada em nós pela natureza, todas as outras maquinarias, técnicas, artifícios ou tecnologias são prolongamentos, conforme venho argumentando há alguns anos (Santaella, 1994, 2003).

A Internet já estava inscrita em nossa constituição simbólica no momento em que o ser humano se tornou bípede, a testa se ergueu, o neocórtex se desenvolveu, dando-se a emergência desse acontecimento único na biosfera, a fala humana, até hoje tão inexplicável quanto a própria vida. Falamos porque o aparelho fonador se organizou através do empréstimo de uma série de órgãos que servem a outras funções que não a da fala. Por isso, a fala já é uma espécie de tecnologia, já é artificial. Depois da fala, vieram as escritas e todas as máquinas para a produção técnica de imagens, sons, audiovisuais e, atualmente, da hipermídia junto com os avanços das simulações computacionais na realidade virtual, robótica e vida artificial.

Essas tecnologias não são tão estranhas a nós quanto parecem ser. São prolongamentos do nosso corpo e da nossa mente. Ao mesmo tempo que o neocórtex não pode parar de crescer, ele não pode continuar crescendo dentro da caixa craniana.
As tecnologias simbólicas, ou tecnologias da inteligência, que hoje já começam a tomar conta também do nosso corpo, são extrassomatizações do cérebro humano. Desde as primeiras imagens nas grutas e das primeiras formas de escritura, o neocórtex vem crescendo, expandindo-se na biosfera, fora da caixa craniana.

Por tudo isso e por acreditar que, dentro de um processo evolutivo que já vem de muito longe, a espécie humana está hoje, de fato, ganhando contornos imprevisíveis, para me referir à heterogeneidade do corpo hibridizado com as tecnologias, venho utilizando, desde 1998, o termo "biocibernético" com um sentido mais amplo do que o de "protético" e de "ciborgue", embora inclua ambos, conforme já explicitei acima. Para me referir à atual necessidade de repensamento do humano na pluralidade de suas dimensões - molecular, corporal, psíquica, social, antropológica, filosófica, etc. - utilizo o termo "pós-humano".

Em suma, nos meus escritos sobre o tema, tenho buscado evidenciar o papel que a transformação tecnológica do corpo vem desempenhando para a emergência do pós-humano, este entendido não só como resultado dessas transformações, mas, sobretudo, como desconstrução das certezas ontológicas e metafísicas implicadas nas tradicionais categorias, geralmente dicotômicas, de sujeito, subjetividade e identidade subjacentes às concepções humanistas que alimentaram a filosofia e as ciências do homem nos últimos séculos e que hoje, inadiavelmente, reclamam por uma revisão radical.

\section{BIBLIOGRAFIA}

ASCOTT, Roy. Telematic Embrace. Visionary Theories of Art, Technology, and Consciousness. Berkeley, University of California Press, 2003.

BRUNO, Fernanda. "Membranas e Interfaces", in Nízia Villaça et al., (orgs.). Que Corpo É Esse? Rio de Janeiro, Mauad, 1999, pp. 98-113.

DONALD, Merlin. Origins of the Modern Mind. Three Stages in the Evolution of Culture and Cognition. Cambridge, MA, Harvard University Press, 1991. 
DYENS, Ollivier. Metal and Flesh. The Evolution of Man: Technology Takes Over. Trad. Evan J. Bibbee e Ollivier Dienz. Cambridge, Mass., The MIT Press, 2001.

FELINTO, Erick. "A Comunicação dos Autômatos: sobre o Imaginário do Pós-Humanismo na Internet", in Galáxia 11, junho de 2006, pp. 107-24.

GIBSON, William. Neuromancer. London, Harper Collins, 1984.

HALBERSTAM, Judith \& LIVINGSTON, Ira. Posthuman Bodies. Bloomington, Indiana University Press, 1995.

HARAWAY, Donna. "A Cyborg Manifesto: Science, Technology, and Socialist-feminism in the Late Twentieth Century", in Simians, Cyborgs, and Women. The Reinvention of Nature. New York, Routledge, 1985, pp. 149-82.

HÄRTEL, Insa \& SCHADE, Sigrid (orgs.). The Body and Representation. International Women's University, 2000.

HAYLES, Katherine. "Complex Dynamics in Literature and Science", in K. Hayles (ed.). Chaos and Order. Chicago, The University of Chicago Press, 1991, pp. 1-36.

"Embodied Virtuality: Or How to Put Body Back into the Picture", in Mary Anne Moser e Douglas MacLeod (eds.). Immersed in Technology. Art and Virtual Environments. Cambridge, Mass., Mit Press, 1996, pp. 1-28.

KAKU, Michio. Visões do Futuro. Como a Ciência Revolucionará o Século XXI. Trad. Maria Luiza X. de A. Borges. Rio de Janeiro, Rocco, 2001.

KELLNER, Douglas. A Cultura da Mídia. Trad. Ivone Castilho Benedetti. Bauru, Edusc, 2001.

LEMOS, André. "Ficçãoo Cientifica Cyberpunk: o Imaginário da Cibercultura", in Conexão - Comunicação e Cultura, UCS, v. 3, no 6, 2004, pp. 9-16.

PEPPERELL, Robert. The Posthuman Condition. Oxford, Intellect, 1995.

SANTAELLA, Lucia. "O Impacto das Novas Tecnologias na Comunicação", in FACOM-Revista da Faculdade de Comunicaç̃̃o da FAAP, ano I, no 2, 1994, pp. 53-61.

Cultura das Mídias. 2a ed. revista e aumentada. São Paulo, Experimento, 1996.

Culturas e Artes do Pós-humano. Da Cultura das Mídias à Cibercultura. São Paulo, Paulus, 2003.

Corpo e Comunicação. Sintoma da Cultura. São Paulo, Paulus, 2004.

SERRES, Michel. "Preface", in L'Oeuf Transparent. Paris, Flammarion, 1986.

SIBILIA, Paula. O Homem Pós-orgânico. Rio de Janeiro, Relume-Dumará, 2002. 